\title{
PLAC1 is an independent predictor of poor survival, and promotes cell proliferation and invasion in cervical cancer
}

\author{
RUJUN CHEN* ${ }^{*}$, CHAN SHENG $^{*}$, RUYUE MA, LIWEN ZHANG, LINA YANG and YAPING CHEN \\ Department of Gynaecology and Obstetrics, Shanghai Fifth People's Hospital, Fudan University, \\ Shanghai 200240, P.R. China
}

Received March 8, 2021; Accepted August 11, 2021

DOI: $10.3892 / \mathrm{mmr} .2021 .12440$

\begin{abstract}
Placenta-specific protein 1 (PLAC1) is inversely associated with survival in several types of cancer. However, whether PLAC1 is involved in the progression of cervical cancer (CC) remains to be elucidated. Therefore, the present study aimed to evaluate the prognostic role of PLAC1 in CC by determining the relationship between clinicopathological factors, PLACl gene expression and survival prognosis using univariate and multivariate Cox proportional-hazards regression analyses. Similarly, Kaplan-Meier curves were evaluated with the log-rank test. Subsequently, gene set enrichment analysis was performed to compare the highand low-PLAC1 expression phenotypes. Functional studies were further conducted in PLAC1-overexpressing HeLa cells and PLAC1-silenced MS751 cells, and western blotting was performed to determine whether PLAC1 promoted CC progression via epithelial-mesenchymal transition (EMT). The findings demonstrated that high expression of PLAC1 was associated with American Joint Committee on Cancer metastasis pathological score and suggested a poor overall survival. 'mTOR complex 1 signaling', 'interferon $\alpha$ response' and 'hypoxia' were differentially enriched in the high-PLAC1 phenotype. Furthermore, PLAC1 promoted the invasion of $\mathrm{CC}$ cells in vitro. E-cadherin expression was decreased in the PLAC1-overexpressing cells, accompanied by increased expression of the mesenchymal markers, Vimentin, MMP2 and Slug, and the opposite effects were observed in PLAC1-silenced cells. Taken together, the present results indicated that high
\end{abstract}

Correspondence to: Dr Lina Yang or Professor Yaping Chen, Department of Gynaecology and Obstetrics, Shanghai Fifth People's Hospital, Fudan University, 801 Heqing Road, Minhang, Shanghai 200240, P.R. China

E-mail: linayang12@fudan.edu.cn

E-mail: chenyaping@5thhospital.com

*Contributed equally

Key words: placenta-specific protein 1, cervical cancer, prognosis, epithelial-mesenchymal transition, tumor metastasis expression of PLAC1 was associated with poor survival and PLAC1 promoted metastasis via EMT in CC.

\section{Introduction}

Cervical cancer (CC) is the fourth most common type of cancer among female patients worldwide (1) and is a major health problem, particularly in developing countries (2). The introduction of a specific human papillomavirus vaccine into clinical practice has led to a gradual reduction in the incidence of CC (3). Over the past two decades, the exploration of the molecular mechanisms underlying tumor development has increased (4). Although significant progress has been achieved, potential prognostic and diagnostic biomarkers must be identified to facilitate the management of patients with $\mathrm{CC}$.

Cancer/testis antigens (CTAs) are a class of tumor-related antigens with restrictive expression patterns that are mostly located on the X chromosome or restricted to cancer and reproductive tissues, and represent a set of extensively researched targets of tumor immunotherapy (5). Placenta-specific protein 1 (PLAC1) is a member of the CTAs; the gene encoding PLAC1 is on the X chromosome (Xq26.3) near the hypoxanthine-guanine phosphoribosyl transferase gene (6). PLAC1 is a small secreted cell-adhesion protein, which has a predicted amino terminal transmembrane domain and a divisible signal peptide of 23 amino acids (6). PLAC1 is normally expressed in placental trophoblasts and the testis, but exhibits extremely low expression in other normal tissues $(7,8)$. In recent decades, PLAC1 has been found to be localized on the surface of tumor cells and be approachable to antibodies (9). High expression levels of PLAC1 have been detected in a broad variety of solid tumors, including liver, digestive tract, mammary, prostatic, ovarian and uterine tumors (10-12). Devor et al (13) reported that PLAC1 was also expressed in human papillomavirus-positive $\mathrm{CC}$, including in four common pathological types. Furthermore, Wang et al (8) revealed that PLAC1, which was elicited by Epstein-Barr virus and expressed in human tumor cells, was an important CTA. Moreover, PLAC1-knockout mice have been reported to show considerable placental defects, with placental layers revealing aberrant differentiation (14). Considering the inherent invasive ability of the placental trophoblast, it has been hypothesized that tumor cells may use the placental mechanisms to facilitate invasion (15). Understanding this process may lead to the development of methods for blocking PLAC1 
expression in tumor cells. Currently, on account of its immunogenicity and carcinogenicity, PLAC1 is on the National Cancer Institute list of 'cancer antigens', which may act as a target for developing vaccines to prevent breast carcinoma (16).

The present study investigated the role of PLAC1 in the proliferation and invasion of $\mathrm{CC}$ cells, and proposed a hypothesis that PLAC1 may be an important oncogenic and prognostic factor in $\mathrm{CC}$.

\section{Materials and methods}

Data preprocessing and survival analysis. RNA-sequencing (RNA-seq) expression data and clinicopathological information (including survival data) from patients with $\mathrm{CC}$ were derived from The Cancer Genome Atlas (TCGA) portal (https://portal.gdc.cancer.gov/). The methods used for sample acquisition, RNA extraction and sequencing were previously described by TCGA Research Network (17). Survival curves were estimated using Kaplan-Meier methods and compared by the log-rank test.

Gene set enrichment analysis (GSEA). The aim of GSEA is to determine the different expression levels of a predefined gene set in two different phenotypes (18). In the present study, GSEA was conducted to examine the significance of survival differences between 'high-PLAC1' and 'low-PLAC1' expression groups based on hallmark collections of gene sets in the Molecular Signatures Database (19) using the official Java GSEA tool (18) (version: 4.1.0, number of permutations $=1,000)$, the two groups were divided by the median expression level. This method identifies genes with large phenotype correlations showing the greatest contribution of enrichment scores in multiple gene sets within a molecular signatures database collection.

Immunohistochemistry (IHC) analysis. The tissue microarray (HUteS154Su01) containing patient clinical information was obtained from Shanghai Outdo Biotech Company and was used to detect the expression levels of PLAC1 in 101 cervical tumor tissues, 35 non-tumor tissues and 18 high-grade squamous intraepithelial lesions (HSILs). The tissue microarray experiment was completed by Shanghai Outdo Biotech Company. The slide was blocked in 10\% goat serum (Sigma-Aldrich; Merck KGaA) for $30 \mathrm{~min}$ at room temperature. Antibody against PLAC1 (1:100; cat. no. sc-365919, Santa Cruz Biotechnology Inc) was added and incubated at $4{ }^{\circ} \mathrm{C}$ overnight. The ready-to-use horseradish peroxidase (HRP)-conjugated secondary antibody (cat. no. K5007; Dako; Agilent Technologies, Inc.) was added and incubated for $30 \mathrm{~min}$ at room temperature. Slides were visualized under a light microscope (Olympus Corporation; cat. no. CX31) at x400 magnification. Semi-quantification of protein expression was determined according to the percentage of positive cells (N) as follows: $0, \leq 5 ; 1,5<\mathrm{N} \leq 25 ; 2,25<\mathrm{N} \leq 50$; $3,50<\mathrm{N} \leq 75$ and $4, \mathrm{~N}>75 \%$. Staining intensity ranged from $0-3$ (0 negative; 1 , weak; 2 , moderate; 3 , strong). , The two scores were multiplied together to calculate the total score, which ranged from 0-12. All IHC data were interpreted by the same qualified pathologist for consistency.

Cell culture. The human CC cell lines CaSki, MS751, C-33A and HeLa, were obtained from the American Type
Culture Collection. All the cells were cultured in DMEM (Sigma-Aldrich; Merck KGaA) supplemented with 10\% FBS (HyClone; Cytiva). All cells were incubated in $5 \% \mathrm{CO}_{2}$ at $37^{\circ} \mathrm{C}$.

RNA silencing and cDNA overexpression. Lentivirus harboring two short hairpin RNAs (shRNAs) targeting PLAC1 gene (PLAC1 shRNA1 and PLAC1 shRNA2) or PLAC1 cDNA were designed and produced by OriGene Technologies, Inc. shRNA targeting firefly luciferase (shLuc) was used as a negative control for RNA silencing, and empty vector was used as a negative control for cDNA overexpression. HeLa cells at 70-80\% confluence were exposed to the lentivirus with PLAC1 cDNA and empty vector (MOI=10), MS751 cells at $70-80 \%$ confluence were exposed to the lentivirus harboring two shRNA (PLAC1 shRNA1 and PLAC1 shRNA2) and shLuc (MOI=10). Subsequently, $1 \mu \mathrm{g} / \mathrm{ml}$ puromycin was used for selection for 10 days. The established cells were then incubated at $37^{\circ} \mathrm{C}$ and $5 \% \mathrm{CO}_{2}$.

Western blot analysis. The cells were harvested using an enzymatic digestion method, then ice-cold lysis buffer (50 mM Tris, $150 \mathrm{mM} \mathrm{NaCl}, 0.5 \%$ EDTA and $0.5 \% \mathrm{NP}-40$ ) was added and incubated for $20 \mathrm{~min}$ at $4^{\circ} \mathrm{C}$. Centrifugation was performed at $13,000 \mathrm{x} \mathrm{g}$ at $4^{\circ} \mathrm{C}$ for $15 \mathrm{~min}$. Total protein concentration was determined using a BCA Protein Quantification kit. Samples (30 $\mu \mathrm{g}$ total proteins) were separated via SDS-PAGE on a $10 \%$ gel and subsequently transferred to a PVDF membrane. Membranes were blocked with 5\% non-fat dry milk for $1 \mathrm{~h}$ at room temperature and incubated with the following primary antibodies overnight at $4^{\circ} \mathrm{C}$ : PLAC1 (1:500; cat. no. sc-365919; Santa Cruz Biotechnology, Inc.), Slug (1:1,000; cat. no. 9585; Cell Signaling Technology), Snail (1:1,000; cat. no. 3879; Cell Signaling Technology), E-cadherin (1:1,000; cat. no. 3195; Cell Signaling Technology), Vimentin (1:1,000; cat. no. 5741; Cell Signaling Technology) and MMP2 (1:1,000; cat. no. 4022; Cell Signaling Technology) and $\beta$-actin (1:10,000; cat. no. MABT825; Sigma-Aldrich; Merck KGaA). After secondary antibody incubation for $1 \mathrm{~h}$ at room temperature (both 1:3,000; HRP-conjugated anti-rabbit and anti-mouse; cat. nos. 7074 and 7076, respectively; Cell Signaling Technology, Inc.), protein expression was determined with the Pierce ECL system (Thermo Fisher Scientific, Inc.). The protein band density was determined using ImageJ (version: 1.53; National Institutes of Health).

Wound healing assay. The established HeLa cells and MS751 cells were seeded into 6-well plates at $80-90 \%$ confluence and grown to a confluent monolayer overnight, then a scratch was made with a $200 \mu \mathrm{l}$ pipette tip. DMEM without FBS was used for cell culture at $37^{\circ} \mathrm{C}$. The cell migratory ability was evaluated by recording the wound area at $48 \mathrm{~h}$ and as percentage of initial wound area at $0 \mathrm{~h}$. The images were visualized under a light microscope. Experiments were performed in triplicate.

Cell migration and invasion assays. The in vitro cell migration and invasion assays were conducted using cell culture chambers (24-well, pore size, $8 \mu \mathrm{m}$; Corning, Inc.). For the invasion assay, the upper chamber was pre-coated with $60 \mu 1$ Matrigel (BD Biosciences) at $37^{\circ} \mathrm{C}$ for $1 \mathrm{~h}$. Cells were collected and resuspended in serum-free medium. Subsequently, cells 
( $2 \times 10^{4} /$ well in migration assay or $5 \times 10^{4} /$ well in invasion assay) were plated in the upper chamber. DMEM containing $10 \%$ FBS was added to the lower chamber. All samples were incubated for 24 or $36 \mathrm{~h}$ at $37^{\circ} \mathrm{C}$ for the cell migration or cell invasion assay, respectively. In the lower surface of the chamber membrane, migrating or invasive cells were fixed with $4 \%$ formaldehyde for $15 \mathrm{~min}$ at room temperature and stained with $0.1 \%$ crystal violet solution (Sigma-Aldrich; Merck KGaA). All experiments were performed in triplicate, and numbers of migrated or invaded cells in five random fields were visualized under a light microscope.

Ethynyl-2'-deoxyuridine (EdU) cell proliferation assay. Detection of EdU incorporation into the DNA was performed with an EdU Apollo DNA in vitro kit (Guangzhou RiboBio Co., Ltd.). According to the manufacturer's instructions, $50 \mu \mathrm{M}$ EdU was used for incorporation. The established cells were seeded in 96 -well plates and incubated overnight at $37^{\circ} \mathrm{C}$. The supernatant was removed by aspiration, and the attached cells were fixed with $100 \mu$ l fixing buffer (4\% polyformaldehyde in PBS) for $30 \mathrm{~min}$ at room temperature. Following incubation with $2 \mathrm{mg} / \mathrm{ml}$ glycine for $10 \mathrm{~min}$ at room temperature, the cells were washed with $1 \mathrm{X}$ PBS. The cells were treated with $100 \mu \mathrm{l} /$ well permeabilization buffer (1X PBS containing $0.5 \%$ Triton $\mathrm{X}-100$ ) for $10 \mathrm{~min}$ at room temperature and incubated with $100 \mu 1 \mathrm{1X}$ Apollo solution for $30 \mathrm{~min}$ at room temperature in the dark. Subsequently, cells were incubated with $100 \mu 1 \mathrm{1X}$ Hoechst 33342 solution for $30 \mathrm{~min}$ at room temperature in the dark. Finally, the cells were observed under a fluorescence microscope.

Colony formation assay. The established HeLa cells and MS751 cells were plated in 6-well plates at the density of 1,000 cells per well and cultured in DMEM supplemented with $10 \% \mathrm{FBS}$ under the condition of $5 \% \mathrm{CO}_{2}$ at $37^{\circ} \mathrm{C}$ for 10 days to form colonies consisting of $\geq 50$ cells. Subsequently, $100 \%$ methanol was used to fix cells for $30 \mathrm{~min}$ at room temperature and $0.1 \%$ crystal violet solution was used to stain the cells for $20 \mathrm{~min}$ at room temperature. The number of colonies was calculated using ImageJ (version no. 1.53) (20). All experiments were performed in triplicate, and representative results are shown.

Statistical analysis. Statistical analysis was performed using $\mathrm{R}$ software (version: 4.0.2) (21). Univariate Cox regression analysis was performed to evaluate survival according to PLAC1 expression and clinicopathological parameters, with median PLAC1 expression used as the boundary. Differences in overall survival between the 'high-PLAC1' and 'low-PLAC1' groups (based on median expression value of PLAC1) were analyzed via the Kaplan-Meier method, with the P-value computed using the 'survival' package in $\mathrm{R}$ software (22). Multivariate Cox analysis was performed to evaluate various parameters associated with the hazard ratio, including age, BMI, number of pregnancies, histology, clinical stage and PLAC1 expression using the 'survival' package in R software. In multivariate Cox analysis, PLAC1 expression was converted into a categorical variable based on the median value to interpret relative risk of PLAC1 expression in CC. Unpaired Student's t, $\chi^{2}$ or Fisher's exact test was performed to compare variables between groups. For multiple comparisons, one-way ANOVA and Tukey's test were used. The Shapiro-Wilk test was performed for the assessment of data normality. Non-normally distributed data were analyzed using Mann-Whitney U test. Normally distributed data were presented as the mean \pm SEM and non-normally distributed data are presented as the median with quartile values $(\mathrm{Q} 1, \mathrm{Q} 3)$. $\mathrm{P}<0.05$ was considered to indicate a statistically significant difference.

\section{Results}

PLAC1 expression and its association with clinicopathological variables. A total of 304 primary CC cases from TCGA database, including both clinical information and RNA-seq data, were analyzed. The median mRNA expression was 37.57 (range, 0-1059.43) for PLAC1. The patient characteristics of TCGA cohort are presented in Table I. The median age of the patients with $\mathrm{CC}$ was 46 years (age range, 20-88 years). In total, $28 \%$ of the patients had a history of smoking. Clinical stages I, II, III and IV comprised 53, 23, 15 and $7 \%$ of the cases (297/304), respectively. The pathological types included cervical squamous cell carcinoma, cervical adenocarcinoma, cervical endocervical mucinous adenocarcinoma and cervical adenosquamous carcinoma, accounting for $83 \%, 10 \%, 5 \%$ and $2 \%$ of the cases, respectively. The median follow-up time for surviving patients with $\mathrm{CC}$ was 21.0 months (follow-up time range, 0-210.51 months).

The expression levels of PLAC1 in CC tissues and normal cervix tissues were subsequently compared, and the result revealed that PLAC1 was highly expressed in CC tissues (Fig. 1A-E). The expression of PLAC1 was significantly higher in all pathological types of cervical cancer than that in normal cervical tissue. Consistent with this, higher PLAC1 was also observed in cervical squamous cell carcinoma samples. However, the increase of PLAC1 expression was not statistically significance in other pathological types of cervical cancer,including endocervical mucinous adenocarcinoma, cervical adenosquamous carcinoma and cervical adenocarcinoma. According to the median expression levels of PLAC1 (37.57), cases were divided into 'high-PLAC1' and 'low-PLAC1' expression groups. $\chi^{2}$ or Fisher's exact test results showed that the two groups had statistically significant differences in the following characteristics: Number of pregnancies, number of live births and American Joint Committee on Cancer metastasis pathological score (Table I).

GSEA based on PLAC1 expression. Based on the median expression value of PLAC1, all subjects were split into two groups, 'high-PLAC1' and 'low-PLAC1' expression groups, and GSEA was performed. Enrichment results in the 'high-PLAC1' phenotype group showed that 33/50 gene sets were upregulated, 24 gene sets were significant at a false discovery rate (FDR) $<25 \%$ and 15 gene sets at FDR $<5 \%$ (Table II), 14 gene sets were significantly enriched at nominal $\mathrm{P}$-value $<1 \%$ and 16 gene sets were significantly enriched at nominal P-value $<5 \%$ (data not shown). The normalized enrichment score of three gene sets was $>2.0$, including 'mTOR complex (mTORC)1 signaling', 'interferon $\alpha$ response' and 'hypoxia' (Fig. 2A-C). Enrichment results in the 
A PLAC1 expression in TCGA-CESC

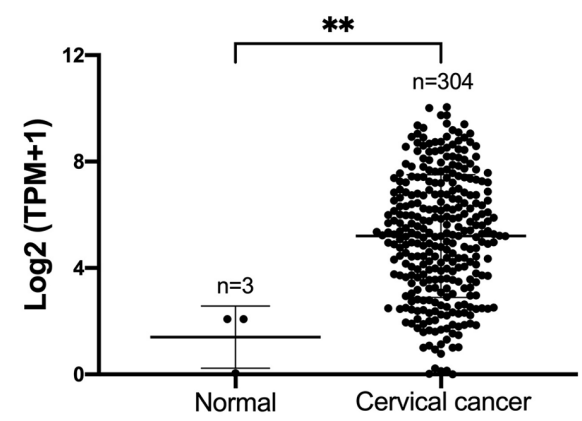

C

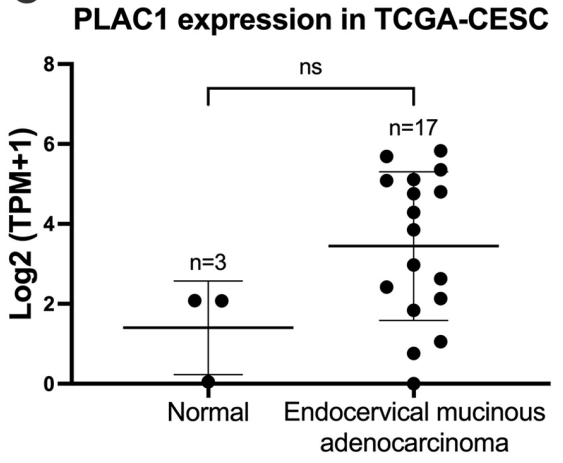

E PLAC1 expression in TCGA-CESC

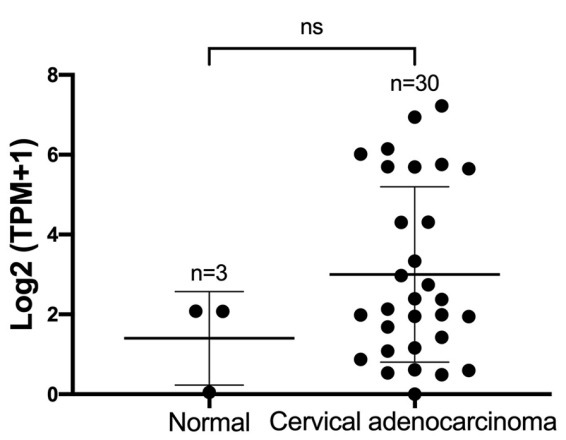

\section{B PLAC1 expression in TCGA-CESC}

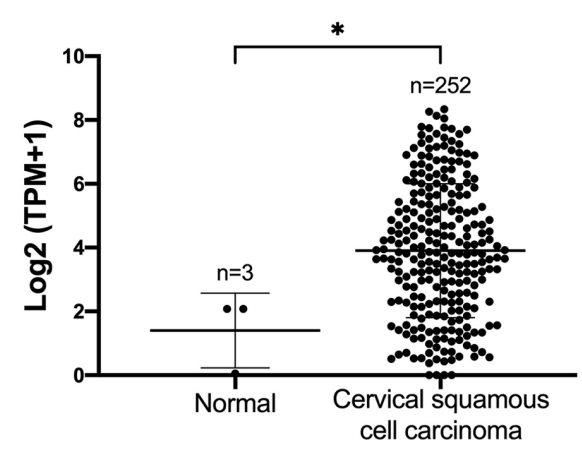

D

PLAC1 expression in TCGA-CESC
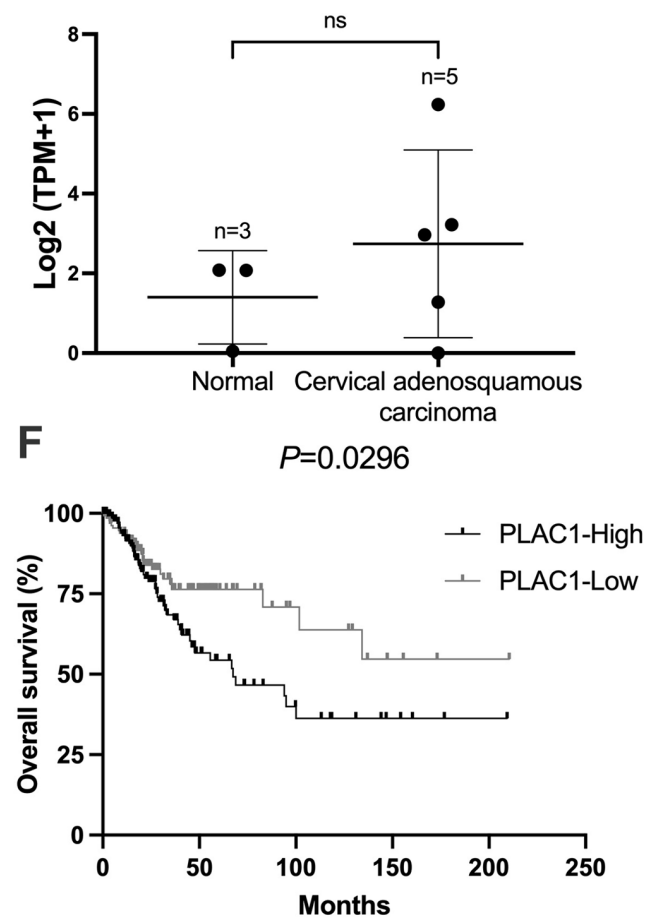

Figure 1. PLAC1 expression is significantly upregulated in CC and high PLAC1 expression is associated with poor survival. (A) PLAC1 expression was upregulated in CC tissues compared with in normal cervical tissues, as revealed using TCGA-CESC dataset. (B) PLAC1 expression was upregulated in cervical squamous cell carcinoma tissues compared with that in normal cervical tissues, as revealed using TCGA-CESC dataset. In other pathological types of CC, (C) endocervical mucinous adenocarcinoma, (D) adenosquamous carcinoma and (E) cervical adenocarcinoma, PLAC1 expression was upregulated, but did not reach a statistically significant level. Data are presented as the mean \pm SEM. ${ }^{\mathrm{P}}<0.05,{ }^{* *} \mathrm{P}<0.01$. (F) Kaplan-Meier survival analysis showed that CC cases with PLAC1-high expression had a worse prognosis than those with PLAC1-low expression ( $\mathrm{P}=0.0296)$. CC, cervical cancer; TCGA-CESC, The Cancer Genome Atlas Cervical Squamous Cell Carcinoma and Endocervical Adenocarcinoma; PLAC1, placenta-specific protein 1; ns, not significant; TPM, transcripts per million.

'low' phenotype showed that 17/50 gene sets were upregulated and no gene sets were significantly enriched at a FDR $<25 \%$ (data not shown). The heat map of the top 50 features for each phenotype is shown in Fig. 2D.

PLAC1 expression in CC tissues and cell lines. The expression levels of PLAC1 in CC tissues, HSILs and normal exocervix were assessed via IHC analysis (Fig. 3A-F). A tissue microarray, comprising $101 \mathrm{CC}$ tissues, 35 paired or unpaired non-cancer cervical tissues and 18 HSILs, was analyzed. CC samples and HSILs exhibited significantly higher expression levels of PLAC1 compared with those in normal tissues (Fig. 3G and H). Moreover, PLAC1 expression was detected in $100 \%(20 / 20)$ of CC samples, compared with in $15 \%(3 / 20)$ of normal tissue (Data not shown). The staining intensity of PLAC1 in CC tissues was more intense than that in normal tissues. A similar trend was observed in the HSILs (Data not shown). To the best of our knowledge, PLAC1 is expressed at low levels in normal cervical cells (23). Protein expression levels of PLAC1 in CC lines, including CaSki, MS751, C-33A and HeLa, were notably upregulated (Fig. 4A). Among these, the expression of PLAC1 in MS751 cells was the highest and the expression of PLAC1 in HeLa cells was relatively low. Therefore, MS751 and HeLa cells were selected for further study.

High PLACl expression is associated with poor survival in $C C$. A total of $304 \mathrm{CC}$ cases with PLAC1 expression data and clinical information across all patient characteristics were derived from TCGA. Three of these cases contained 
Table I. Patient characteristics of The Cancer Genome Atlas cohort.

\begin{tabular}{|c|c|c|c|c|c|}
\hline \multirow[b]{2}{*}{ Characteristic } & \multirow[b]{2}{*}{ Total } & \multicolumn{2}{|c|}{ PLAC1 expression level } & \multirow[b]{2}{*}{$\chi^{2}$} & \multirow[b]{2}{*}{ P-value } \\
\hline & & Low & High & & \\
\hline Age at diagnosis, years & & & & 0.000 & $>0.999$ \\
\hline$<46$ & 145 & 72 & 73 & & \\
\hline$\geq 46$ & 159 & 80 & 79 & & \\
\hline BMI & & & & 0.096 & 0.757 \\
\hline$<24$ & 81 & 42 & 39 & & \\
\hline$\geq 24$ & 178 & 87 & 91 & & \\
\hline Menopausal status & & & & 0.514 & 0.774 \\
\hline Premenopausal & 124 & 62 & 62 & & \\
\hline Perimenopausal & 28 & 13 & 15 & & \\
\hline Postmenopausal & 82 & 44 & 38 & & \\
\hline Pregnancies count total & & & & 5.188 & 0.023 \\
\hline$<5$ & 191 & 105 & 86 & & \\
\hline$\geq 5$ & 73 & 28 & 45 & & \\
\hline Pregnancies count live birth & & & & 4.760 & 0.029 \\
\hline$<5$ & 220 & 116 & 104 & & \\
\hline$\geq 5$ & 40 & 13 & 27 & & \\
\hline Smoking status & & & & 0.405 & 0.524 \\
\hline Yes & 86 & 46 & 40 & & \\
\hline No & 218 & 106 & 112 & & \\
\hline Smoking years & & & & 0.000 & 1.000 \\
\hline$<19$ & 43 & 23 & 20 & & \\
\hline$\geq 19$ & 43 & 23 & 20 & & \\
\hline Smoking pack years & & & & 2.616 & 0.106 \\
\hline$<10$ & 32 & 13 & 19 & & \\
\hline$\geq 10$ & 54 & 33 & 21 & & \\
\hline ECOG score & & & & - & $0.693^{\mathrm{a}}$ \\
\hline 0 & 79 & 40 & 39 & & \\
\hline 1 & 83 & 37 & 46 & & \\
\hline 2 & 9 & 5 & 4 & & \\
\hline 4 & 1 & - & 1 & & \\
\hline Histology & & & & - & $0.250^{\mathrm{a}}$ \\
\hline Cervical squamous cell carcinoma & 252 & 121 & 131 & & \\
\hline Cervical adenocarcinoma & 30 & 20 & 10 & & \\
\hline Cervical endocervical mucinous adenocarcinoma & 17 & 8 & 9 & & \\
\hline Cervical adenosquamous carcinoma & 5 & 3 & 2 & & \\
\hline HPV types positive & & & & - & $0.580^{\mathrm{a}}$ \\
\hline HPV16 & 12 & 5 & 7 & & \\
\hline HPV18 & 3 & 1 & 2 & & \\
\hline Others & 7 & 1 & 6 & & \\
\hline Clinical stage & & & & 1.709 & 0.635 \\
\hline $\mathrm{I}$ & 161 & 85 & 76 & & \\
\hline II & 69 & 32 & 37 & & \\
\hline III & 45 & 21 & 24 & & \\
\hline IV & 22 & 13 & 9 & & \\
\hline AJCC tumor pathological score & & & & - & $0.553^{\mathrm{a}}$ \\
\hline $\mathrm{T}_{\mathrm{X}}$ & 17 & 6 & 11 & & \\
\hline Tis & 1 & 0 & 1 & & \\
\hline $\mathrm{T}_{1}$ & 140 & 72 & 68 & & \\
\hline $\mathrm{T}_{2}$ & 71 & 40 & 31 & & \\
\hline $\mathrm{T}_{3}$ & 20 & 9 & 11 & & \\
\hline $\mathrm{T}_{4}$ & 10 & 6 & 4 & & \\
\hline
\end{tabular}


Table I. Continued.

\begin{tabular}{|c|c|c|c|c|c|}
\hline \multirow[b]{2}{*}{ Characteristic } & \multirow[b]{2}{*}{ Total } & \multicolumn{2}{|c|}{ PLAC1 expression level } & \multirow[b]{2}{*}{$\chi^{2}$} & \multirow[b]{2}{*}{ P-value } \\
\hline & & Low & High & & \\
\hline AJCC metastasis pathological score & & & & 7.167 & 0.028 \\
\hline $\mathrm{M}_{\mathrm{X}}$ & 128 & 56 & 72 & & \\
\hline $\mathrm{M}_{0}$ & 115 & 67 & 48 & & \\
\hline $\mathrm{M}_{1}$ & 11 & 8 & 3 & & \\
\hline AJCC nodes pathological score & & & & 3.764 & 0.152 \\
\hline $\mathrm{N}_{\mathrm{X}}$ & 66 & 29 & 37 & & \\
\hline $\mathrm{N}_{0}$ & 133 & 76 & 57 & & \\
\hline $\mathrm{N}_{1}$ & 60 & 28 & 32 & & \\
\hline
\end{tabular}

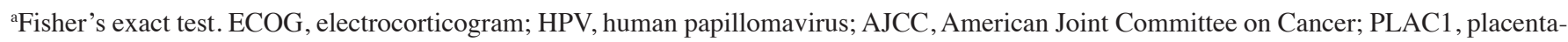
specific protein 1 .
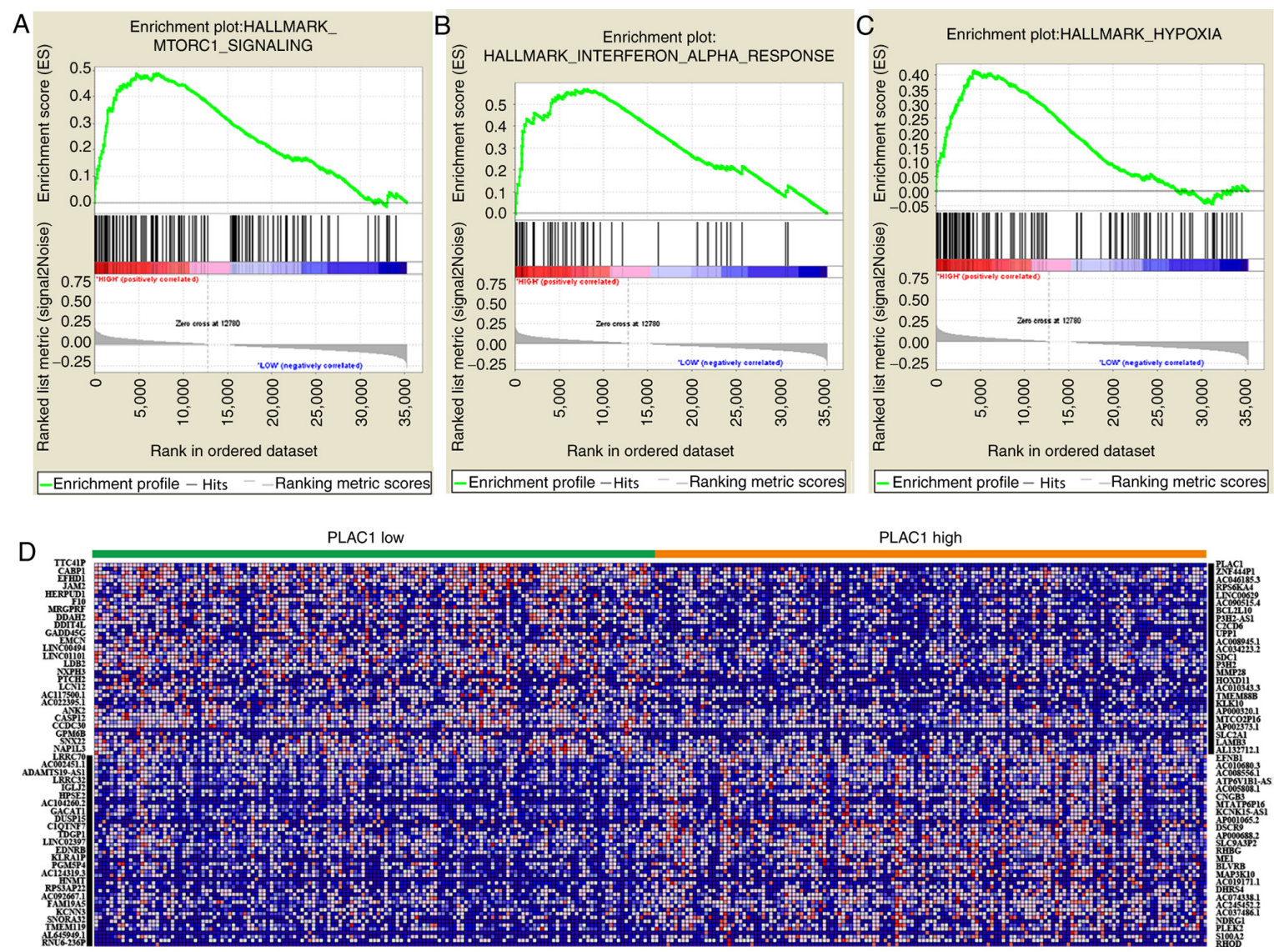

Figure 2. Gene set enrichment analysis. (A) 'mTORC1 signaling', (B) 'interferon $\alpha$ response' and (C) 'hypoxia' were differentially enriched in the 'high-PLAC1' expression phenotype. (D) Heat map of the top 50 features for each phenotype. PLAC1, placenta-specific protein 1; mTORC1, mTOR complex 1.

matched paracancerous samples. A total of three normal cervical samples were excluded from the survival analysis. It was demonstrated that high expression of PLAC1 was a risk factor for the poor prognosis of patients with CC (Fig. 1F). Similarly, the clinical data contained in the tissue microarray also suggested that patients with high expression of PLAC1 had a poor survival (Fig. 3I).

Univariate Cox analysis suggested that four characteristics were associated with prognosis, including BMI, clinical stage,
American Joint Committee on Cancer tumor pathological score and PLAC1 expression (as a continuous independent variable) (Table III). Multivariate Cox analysis suggested age (hazard ratio=1.02; $\mathrm{P}=0.047$ ), clinical stage (hazard ratio=1.68; $\mathrm{P}<0.001$ ) and PLAC1 expression (hazard ratio=1.92; $\mathrm{P}=0.032$ ) were associated with the prognosis of patients with CC (Table III). Similarly, PLAC1 expression as a binary variable (according to median expression value of 37.57) was associated with poor prognostic clinicopathological characteristics (Table III). Age, 
Table II. Gene sets enriched in 'high-PLAC1' phenotype (FDR<0.05).

\begin{tabular}{|c|c|c|c|c|c|}
\hline Gene set & Size & NES & P-value & FDR & Rank at max \\
\hline MTORC1 SIGNALING & 132 & 2.485 & $<0.001$ & $<0.001$ & 7,108 \\
\hline INTERFERON ALPHA RESPONSE & 48 & 2.381 & $<0.001$ & $<0.001$ & 7,782 \\
\hline HYPOXIA & 127 & 2.130 & $<0.001$ & 0.001 & 4,222 \\
\hline MYC TARGETS V1 & 135 & 1.993 & $<0.001$ & 0.002 & 7,970 \\
\hline E2F TARGETS & 128 & 1.983 & $<0.001$ & 0.002 & 8,358 \\
\hline GLYCOLYSIS & 130 & 1.968 & $<0.001$ & 0.002 & 5,077 \\
\hline P53 PATHWAY & 126 & 1.949 & $<0.001$ & 0.002 & 5,817 \\
\hline TNFA SIGNALING VIA NFKB & 121 & 1.919 & $<0.001$ & 0.001 & 7,875 \\
\hline PI3K AKT MTOR SIGNALING & 66 & 1.899 & $<0.001$ & 0.001 & 7,224 \\
\hline MYC TARGETS V2 & 32 & 1.832 & $<0.001$ & 0.004 & 8,037 \\
\hline REACTIVE OXIGEN SPECIES PATHWAY & 33 & 1.800 & 0.009 & 0.004 & 6,849 \\
\hline INTERFERON GAMMA RESPONSE & 124 & 1.783 & $<0.001$ & 0.005 & 7,379 \\
\hline APOPTOSIS & 100 & 1.537 & $<0.001$ & 0.026 & 7,310 \\
\hline ESTROGEN RESPONSE LATE & 117 & 1.509 & $<0.001$ & 0.029 & 4,559 \\
\hline CHOLESTEROL HOMEOSTASIS & 49 & 1.474 & 0.021 & 0.038 & 6,553 \\
\hline
\end{tabular}

FDR, false discovery rate; NES, normalized enrichment score; PLAC1, placenta-specific protein 1
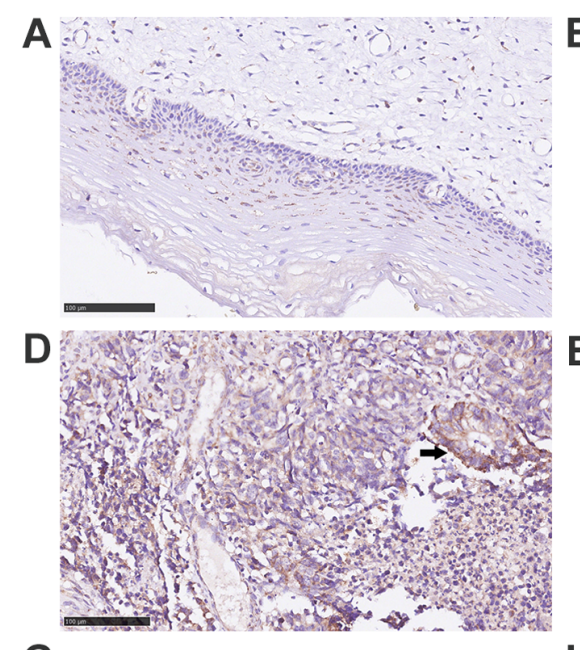

G

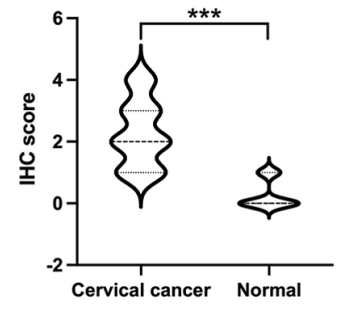

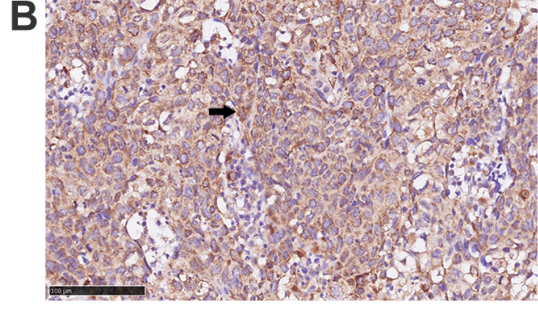

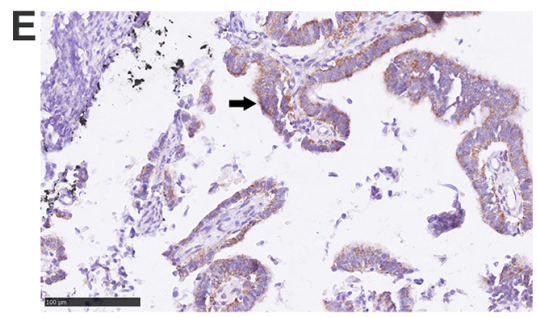

H

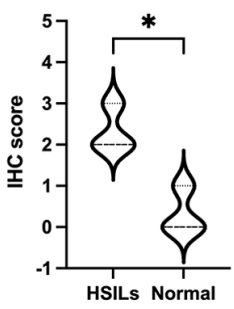

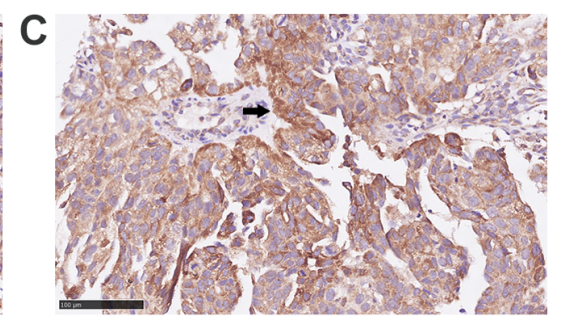

F
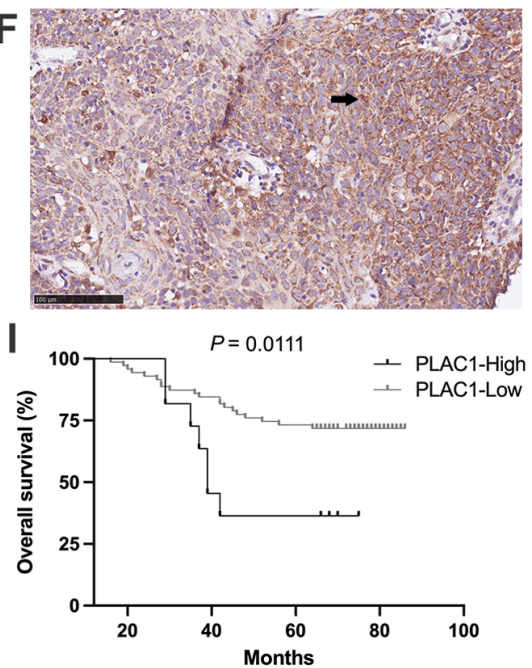

Figure 3. Immunohistochemical evaluation of PLAC1 in (A) normal exocervix, (B) cervical squamous cell carcinoma, (C) cervical adenocarcinoma (D) cervical adenosquamous carcinoma, (E) small cell neuroendocrine cervical cancer and (F) high-grade squamous intraepithelial lesions. Black arrows show PLAC1 expression. IHC score values of PLAC1 were significantly higher in (G) CC and (H) HSILs than those in normal tissues. Bars indicate the median and interquartile range. ${ }^{*} \mathrm{P}<0.05,{ }^{* * *} \mathrm{P}<0.001$. (I) Patients with high expression of PLAC1 had poor overall survival (P=0.0111). Magnification, $\mathrm{x} 200$. PLAC1, placenta-specific protein 1 ; IHC, immunohistochemistry.

BMI, number of pregnancies, histology, clinical stage and PLAC1 expression were incorporated in the multivariate Cox model. All six variables were consistent with the proportional hazard assumption (P-value of each component was $<0.05$, and Global Schoenfeld test $\mathrm{P}>0.05)$.
PLAC1 promotes cell proliferation, migration and invasion in $C C$. Since the expression of PLAC1 is associated with metastasis and cell proliferation in $\mathrm{CC}$, the impact of overexpression or knockdown of PLACl on proliferation and invasion in CC cell lines was examined. PLAC1-overexpressing HeLa cells 
Table III. Overall survival and associations with clinicopathological characteristics determined using Cox regression analysis.

Univariate Cox analysisMultivariate Cox analysis

\begin{tabular}{lcccccc}
\hline Characteristic & HR & $95 \%$ CI & P-value & HR & $95 \%$ CI & P-value \\
\hline Age at diagnosis, years & 1.02 & $1.00-1.03$ & 0.078 & 1.02 & $1.00-1.05$ & 0.047 \\
BMI & 0.95 & $0.91-1.00$ & 0.033 & 0.99 & $0.94-1.03$ & 0.533 \\
Pregnancies count total & 1.03 & $0.94-1.12$ & 0.594 & 0.98 & $0.88-1.09$ & 0.692 \\
Pregnancies count live birth & 1.05 & $0.94-1.17$ & 0.407 & - & - & - \\
Menopausal status & 1.08 & $0.81-1.43$ & 0.612 & - & - & - \\
Smoking years & 0.98 & $0.92-1.05$ & 0.635 & - & - & - \\
Smoking pack years & 1.01 & $0.98-1.04$ & 0.565 & - & - & - \\
ECOG score & 1.32 & $0.76-2.30$ & 0.329 & - & - & - \\
Histology & 1.11 & $0.75-1.64$ & 0.603 & 1.25 & $0.81-1.93$ & 0.308 \\
HPV types positive & 1.37 & $0.60-3.12$ & 0.455 & - & - & - \\
Clinical stage & 1.47 & $1.18-1.83$ & $<0.001$ & 1.68 & $1.27-2.23$ & $<0.001$ \\
AJCC tumor pathological score & 1.34 & $1.00-1.78$ & 0.047 & - & - & - \\
AJCC metastasis pathological score & 0.77 & $0.47-1.25$ & 0.295 & - & - & - \\
AJCC nodes pathological score & 0.78 & $0.52-1.17$ & 0.233 & - & - & - \\
PLAC1 expression & 1.70 & $1.05-2.74$ & $0.031^{\mathrm{a}}$ & 1.92 & $1.06-3.51$ & $0.032^{\mathrm{b}}$ \\
\hline
\end{tabular}

${ }^{\mathrm{a} A s}$ a continuous variable. ${ }^{\mathrm{b}}$ As a categorical variable. ECOG, electrocorticogram; HPV, human papillomavirus; AJCC, American Joint Committee on Cancer; PLAC1, placenta-specific protein 1; HR, hazard ratio; CI, confidence interval.

and PLAC1-silenced MS751 cells with shRNA2 (Fig. 4B) were employed for functional studies. Colony formation and EdU incorporation assays were used to investigate the effect of PLAC1 on cell proliferation. The results demonstrated that overexpression of PLAC1 significantly promoted cell proliferation, whereas PLAC1 silencing inhibited proliferation (Fig. 4C-E). Furthermore, as confirmed by wound healing assay (Fig. 4F and G), the motility of cells was significantly increased in PLAC1-overexpressing group and decreased in PLAC1-silenced group compared with that in control group. Transwell migration and invasion assays were performed to estimate the effect of PLAC1 on cell migration and invasion. The results revealed that overexpression of PLAC1 facilitated cell migration and invasion (Fig. $4 \mathrm{H}$ ), whereas PLAC1 silencing in MS751 cells suppressed migration and invasion (Fig. 4I). These results suggested that PLAC1 may exert a critical role in regulating cell proliferation and invasion in CC.

PLAC1 enhances invasion via the epithelial-mesenchymal transition (EMT) signaling pathway. Since EMT is an essential process in the pathogenesis of metastasis in tumor cells (24), studies were subsequently conducted to investigate whether EMT was a causative factor for PLAC1-induced changes in cell motility. Compared with control cells, the expression of E-cadherin, one of most common epithelial markers, was decreased in the PLAC1-overexpressing HeLa cells, accompanied by an increase in the expression of the mesenchymal markers, Slug, MMP2 and Vimentin (Fig. 5A and B).

As Slug and Snail are transcriptional regulators that have been substantiated as crucial EMT regulators through inhibiting the epithelial phenotype-related genes and activating mesenchymal markers (25), we then evaluated whether E-cadherin, Snail and Slug were affected in the MS751 cells infected with PLAC1-shRNA. The results showed that silencing of PLAC1 inhibited the expression of Slug and Snail, but upregulated E-cadherin (Fig. 5C and D), suggesting that decreased expression of PLAC1 may increase the expression of E-cadherin by suppressing Slug and Snail. Mesenchymal marker Vimentin was downregulated in PLAC1-silenced cells. Taken together, these findings indicated that PLAC1 may serve a crucial role in carcinogenesis by activating the EMT-related signaling pathways.

\section{Discussion}

The present study analyzed the clinical information and RNA-seq data from 304 patients with CC in TCGA database. Verification studies using IHC confirmed that the expression levels of PLAC1 were significantly increased in CC tissues and HSILs. It was identified that high PLAC1 expression indicated a poor prognosis. Furthermore, multivariate survival analysis revealed that high PLAC1 expression was a poor prognostic parameter for overall survival. Functional studies demonstrated that overexpression of PLAC1 promoted cell proliferation and motility. Collectively, these data indicated that PLAC1 may be a prognostic marker and therapeutic target in CC.

Previous studies examining PLAC1 in other tumor types suggested that higher relative expression of PLAC1 had an association with poor survival $(26,27)$. Inhibition of PLAC1 in breast cancer cells markedly affected motility, migration and invasion, and induced a $\mathrm{G}_{1}-\mathrm{S}$ cell cycle block that almost completely suppressed proliferation (10). Additionally, patients with gastric adenocarcinoma exhibiting relatively low 
A

B

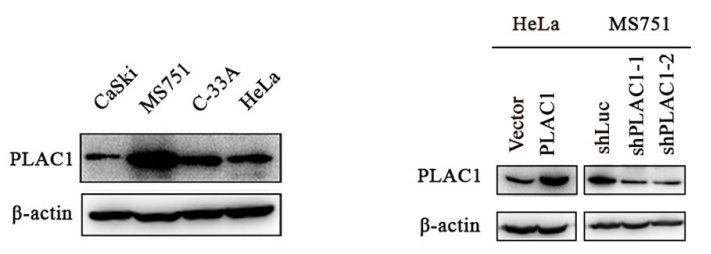

D

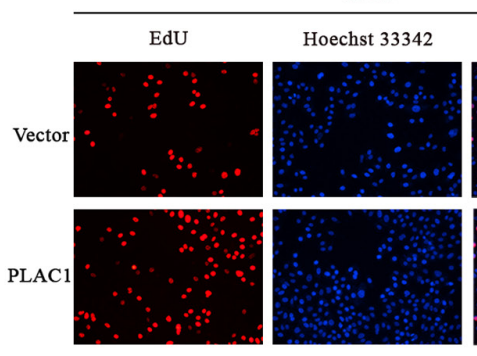

F

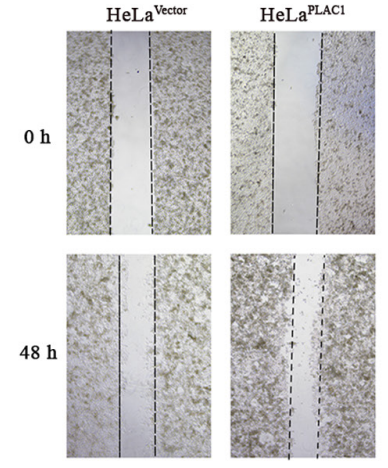

H
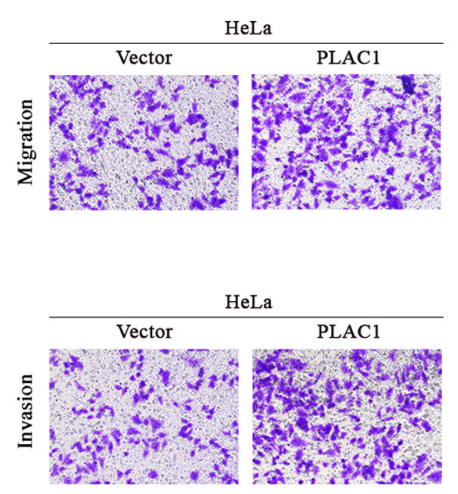

C
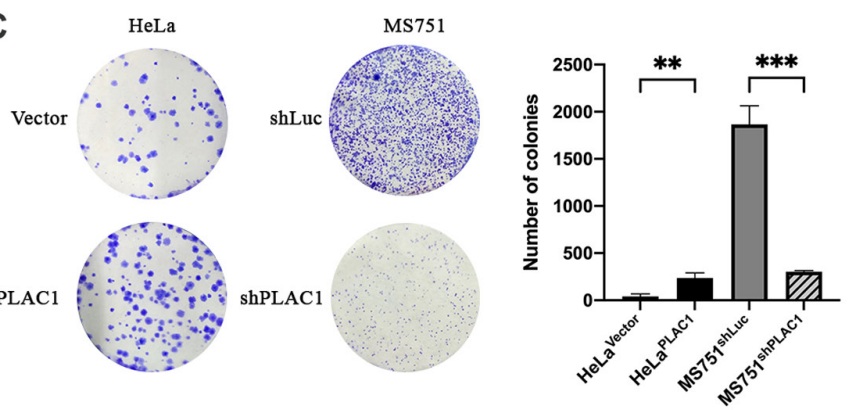

E

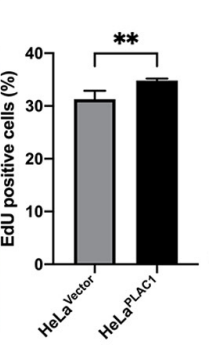

G
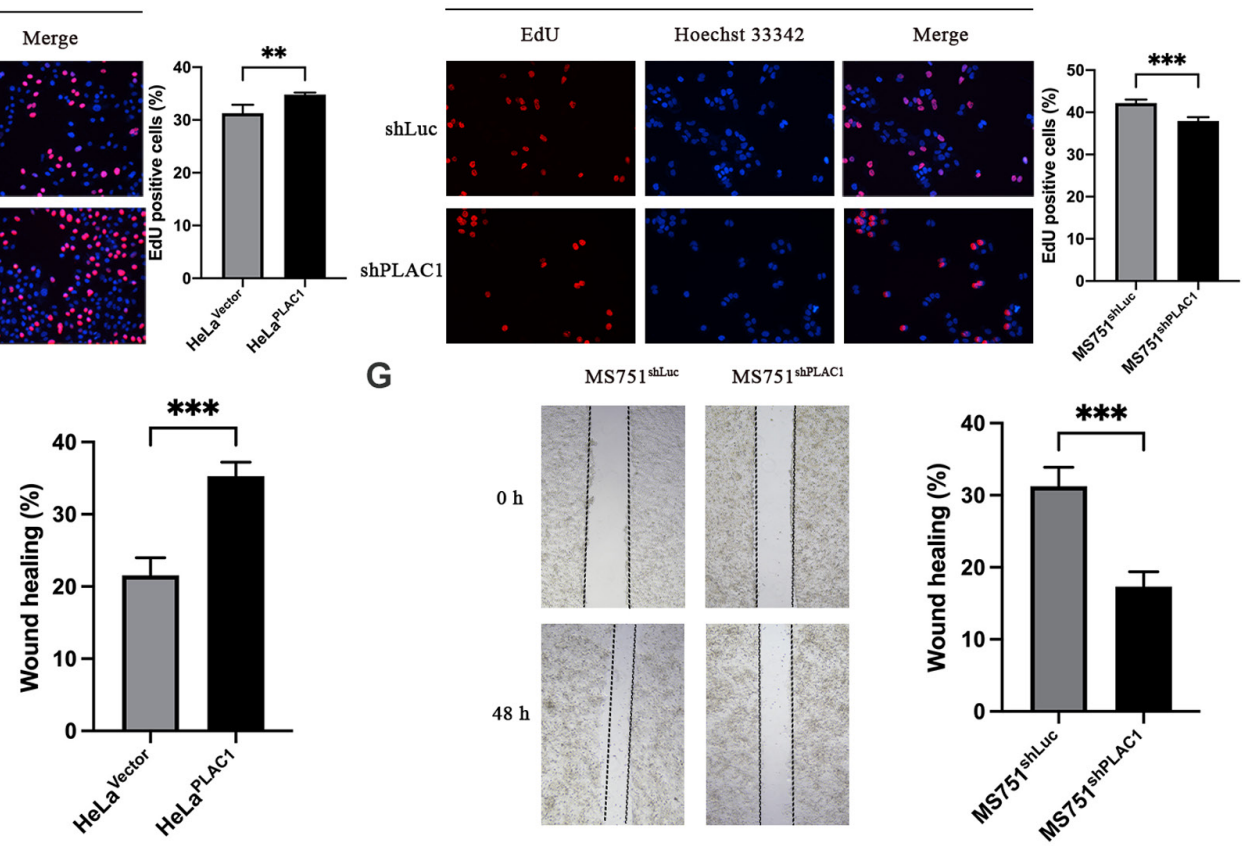

MS751 $1_{\text {stluc }}^{\text {MS751 }} 1^{\text {sbPLAC1 }}$
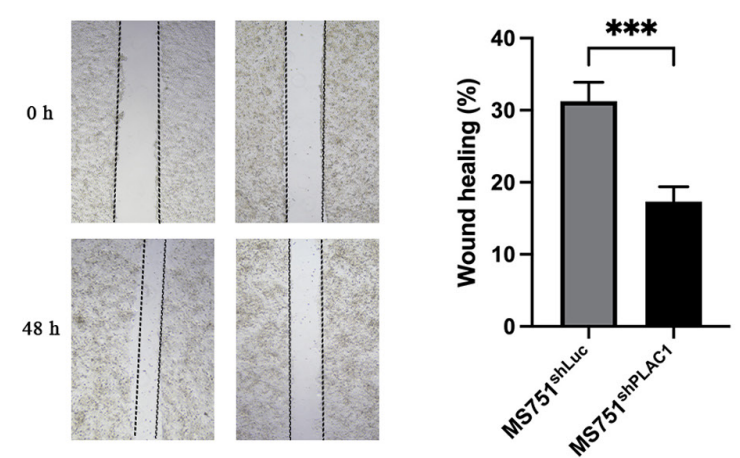

I
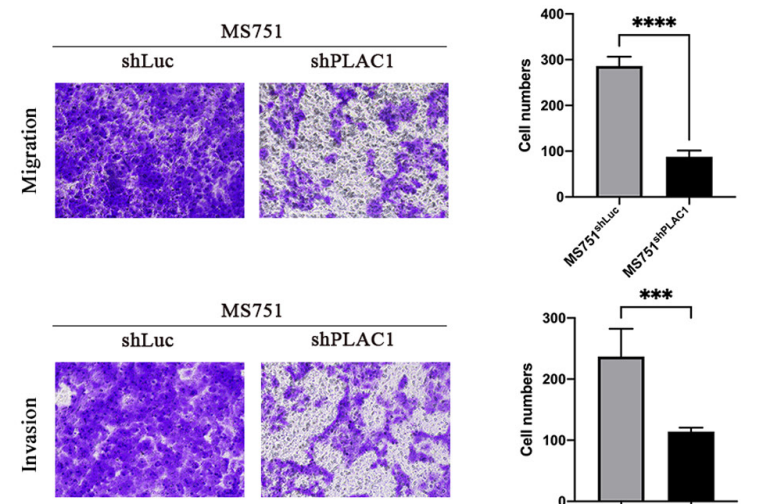

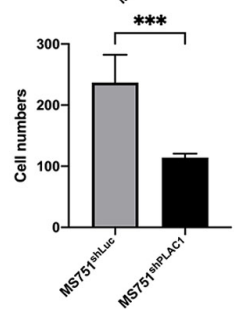

Figure 4. PLAC1 promotes proliferation and motility in CC. (A) Expression of PLAC1 in cervical cancer cell lines CaSki, MS751, C-33A and HeLa. (B) PLAC1 was upregulated in PLAC1-overexpressing HeLa cells and downregulated in PLAC1-silenced MS751 cells. (C) Cell proliferation determined using colony formation assay. (D and E) Cell proliferation measured using EdU incorporation assay. Magnification, x200. (F and G) Cell motility examined using wound healing assay. Magnification, $\mathrm{x} 40$. (H and I) Cell motility detected using Transwell assay. Magnification, $\mathrm{x} 200$. Data are presented as the mean $\pm \mathrm{SEM}$. $\mathrm{P}<0.05$, ${ }^{* *} \mathrm{P}<0.01,{ }^{* * *} \mathrm{P}<0.001,{ }^{* * * * *} \mathrm{P}<0.0001$. PLAC1, placenta-specific protein 1; sh, short hairpin; EdU, ethynyl-2'-deoxyuridine.

PLAC1 expression had a longer survival time compared with those exhibiting higher PLAC1 expression (26). Furthermore, numerous studies related to hepatocellular carcinoma (11), colorectal cancer (28), ovarian cancer (29), uterine cancer (30) and prostate cancer (31) have reported that PLAC1 expression was positively correlated with clinical parameters, including clinical stage, grade and survival outcome. All these previous reports showed similar results as those obtained in the present study, as high PLAC1 expression levels indicated poor prognosis in CC.

Based on the GSEA, 33 gene sets exhibited significant differences in the 'high-PLAC1' phenotype group; however, no gene set enrichment exhibited significant differences in the 'low-PLAC1' phenotype group. 'mTORC1 signaling', 
A

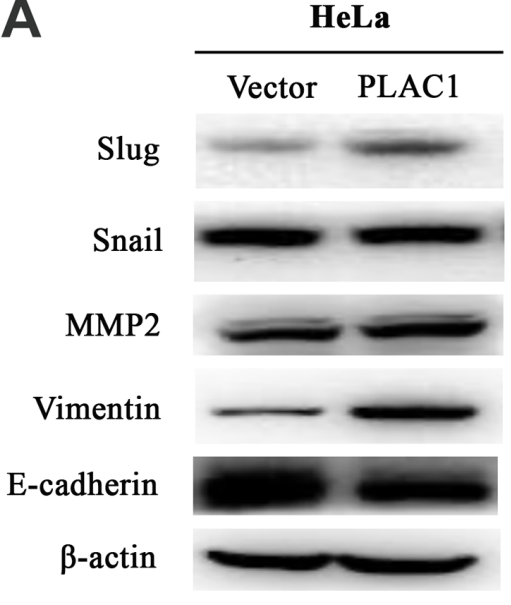

B

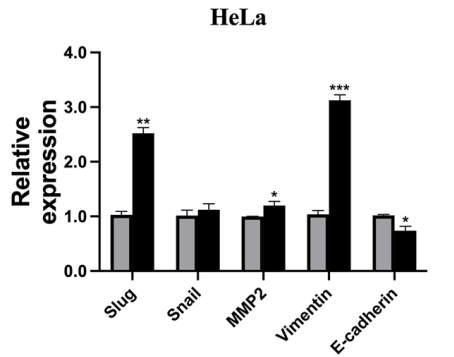

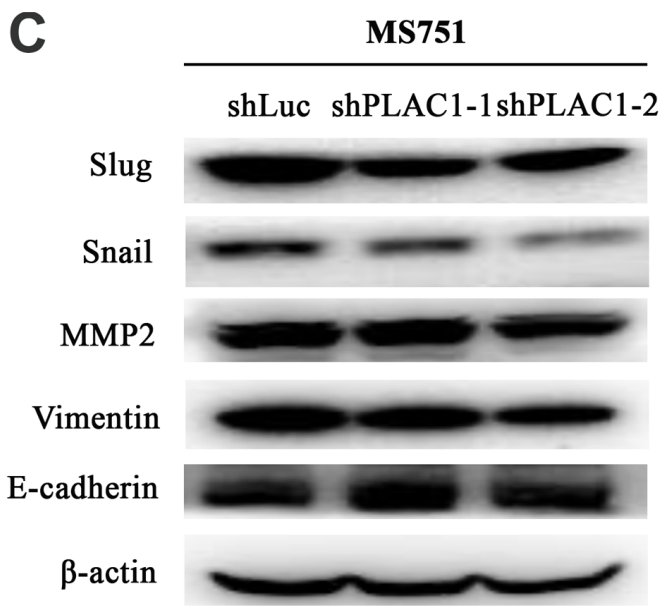

D

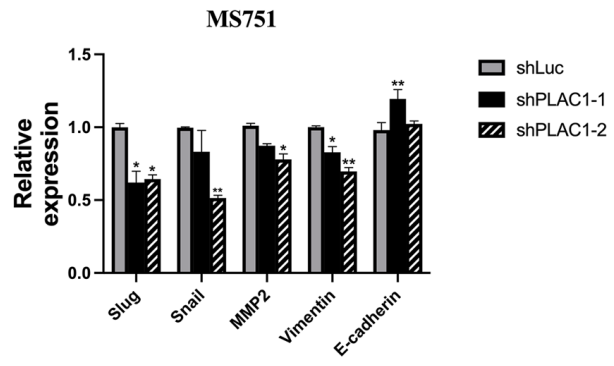

Figure 5. Overexpression of PLAC1 significantly increases the expression of EMT-associated protein and knockdown of PLAC1 significantly decreases the expression of EMT-associated protein. (A and B) Overexpression of PLAC1 in HeLa cells significantly increased the expression of Slug, MMP2 and Vimentin, but decreased the expression of E-cadherin, as detected via western blot analysis. (C and D) Knockdown of PLAC1 in MS751 cells significantly decreased the expression of Slug, Snail, MMP2, and Vimentin but increased the expression of E-cadherin, as detected via western blot analysis. The results were normalized to the expression of $\beta$-actin. ${ }^{*} \mathrm{P}<0.05,{ }^{* *} \mathrm{P}<0.01,{ }^{* * *} \mathrm{P}<0.001$. PLAC1, placenta-specific protein 1 ; sh, short hairpin; EMT, epithelial-mesenchymal transition.

'interferon $\alpha$ response' and 'hypoxia' were differentially enriched in the 'high-PLAC1' expression phenotype. mTORC1 is sensitive to rapamycin, and is typically activated by numerous stimuli and essential signaling pathways, such as PI3K, MAPK and AMP-activated protein kinase, to control cell proliferation and survival (32). mTORC1 pathways have been reported be involved in various types of cancer (33). Kremer et al (34) revealed that activation of mTOR signaling led to the survival of CC cells. Moreover, microRNA-99 has been reported to inhibit CC cell proliferation and invasion by targeting the mTOR signaling pathway (35), whereas AKT inhibitors may promote cell death in CC by disrupting mTOR signaling and glucose uptake (36). Improving the anti-tumoral interferon $\alpha$ response can be used to treat hematological malignancies and solid tumors in cancer immunotherapy $(37,38)$. Hypoxia, an important regulator in tumor growth (39), has been shown to be associated with poor survival and radiotherapy resistance, and numerous molecules in the hypoxia-response pathway are candidates as therapeutic targets $(40,41)$. Furthermore, Pilch et al (42) reported that hypoxia stimulated the expression of tumor angiogenesis factors in CC cells and derived fibroblasts. Therefore, most gene sets enriched in the high expression group have previously been associated with tumor pathogenesis.

To investigate the carcinogenic characteristics of PLAC1 in the tumor process, we overexpressed PLAC1 in HeLa cells and used PLAC1-specific shRNA to knockdown PLAC1 in MS751 cells. Subsequently, the effects of PLAC1 on cell proliferation, migration and invasion were assessed. The present results suggested that cell proliferation was inhibited by PLAC1 silencing in MS751 cells. Furthermore, overexpression of PLAC1 in HeLa cells increased cell proliferation, which indicated a role for PLAC1 in enhancing tumor cell proliferation. Furthermore, the current results indicated that PLAC1 facilitated migration and invasion in tumor cells, as shown by the fact that PLAC1-overexpressing HeLa cells had a stronger cell motility, and PLAC1 silencing inhibited migration and invasion in MS751 cells, as determined using in vitro wound healing and Transwell assays.

The present study also investigated whether the changes in tumor cell migration and invasion were due to EMT. EMT is a crucial physiological process affecting the invasion and migration of cancer cells (43). Epithelial cells gain mesenchymal characteristics via dedifferentiation processes that result in the loss of epithelial characteristics. In this process, downregulation of E-cadherin, an epithelial cell adhesion marker, is considered to be an essential step (44). Vimentin, a mesenchymal marker, and the most well-studied inhibitors of E-cadherin, such as Snail, Slug, Twist, ZEB-1 and ZEB-2, which act by binding to E-boxes of E-cadherin promoter and inhibiting its transcription, actively participate in the EMT process (45). In the present study, PLAC1 silencing enhanced E-cadherin expression, along with a noticeable reduction in vimentin and MMP2 expression. Moreover, the expression 
levels of Slug and Snail were downregulated, which supported the aforementioned findings. Taken together, these results suggested that PLAC1 served an oncogenic role via EMT, thus promoting metastasis in $\mathrm{CC}$. Moreover, it was confirmed that PLAC1 may be a candidate oncogene for CC. Future studies will be conducted to investigate the underlying molecular mechanisms by which PLAC1 regulates EMT in CC.

In conclusion, the present study demonstrated that PLAC1 was a key regulator for $\mathrm{CC}$ progression by promoting cell proliferation, migration and invasion via activation of the EMT process, and high expression of PLAC1 was revealed to be a marker of poor prognosis in patients with CC. RNA-seq data from CC samples, as reported by TCGA, were analyzed; however, matched protein data were not available to support the elevation of PLAC1 transcriptome expression. Therefore, a tissue microarray was used to validate the higher expression levels of PLAC1 in CC tissues compared with in non-tumor tissues. However, the expression levels of PLAC1 were not verified in the serum of patients with CC. Thus, further studies are required to evaluate the prognostic value and feasibility of serum PLAC1 as a predictive marker in a larger, prospective cohort of patients with $\mathrm{CC}$, and to elucidate the specific molecular mechanisms of PLAC1 in CC.

\section{Acknowledgements}

The tissue microarray experiment was completed by Shanghai Outdo Biotech Company.

\section{Funding}

The project was supported by Health Profession Clinical Research Funds of Shanghai Municipal Health Commission (grant no. 20194Y0259), Natural Science Research Funds of Minhang District, Shanghai (grant no. 2019MHZ038) and Key Medical Specialty funded by Shanghai Fifth People's Hospital, Fudan University (grant no. 2020WYZDZK13)

\section{Availability of data and materials}

The datasets used and/or analyzed during the current study are available from the corresponding author on reasonable request. The results shown here are in part based upon data generated by TCGA Research Network: https:/www.cancer.gov/tcga

\section{Authors' contributions}

LY and YC conceived and designed the project. RM, LZ, CS and RC completed the research work. CS and RC collected data, performed statistical analyses and drafted the manuscript. All authors read and approved the final manuscript. RM and $\mathrm{RC}$ confirm the authenticity of all the raw data.

\section{Ethics approval and consent to participate}

Use of the tissue microarray (HUteS154Su01) in this study has been approved by the Ethics Committee of the Shanghai Outdo Biotech Company (approval no. YB M-05-01). The tissue microarray experiment was completed by Shanghai Outdo Biotech Company.

\section{Patient consent for publication}

Not applicable.

\section{Competing interests}

The authors declare that they have no competing interests.

\section{References}

1. Ferlay JEM, Lam F, Colombet M, Mery L and Piñeros M: Znaor a, Soerjomataram I, Bray F. Global Cancer Observatory: Cancer Today. International Agency for Research on Cancer, Lyon, France, 2020.

2. Arbyn M, Weiderpass E, Bruni L, de Sanjosé S, Saraiya M, Ferlay $\mathrm{J}$ and Bray F: Estimates of incidence and mortality of cervical cancer in 2018: A worldwide analysis. Lancet Glob Health 8: e191-e203, 2020.

3. Wang R, Pan W, Jin L, Huang W, Li Y, Wu D, Gao C, Ma D and Liao S: Human papillomavirus vaccine against cervical cancer: Opportunity and challenge. Cancer Lett 471: 88-102, 2020.

4. Hermyt E, Zmarzły N, Grabarek B, Kruszniewska-Rajs C, Gola J, Jęda-Golonka A, Szczepanek K, Mazurek U and Witek A: Interplay between miRNAs and Genes Associated with Cell Proliferation in Endometrial Cancer. Int J Mol Sci 20: E6011, 2019.

5. Scanlan MJ, Gure AO, Jungbluth AA, Old LJ and Chen YT: Cancer/testis antigens: An expanding family of targets for cancer immunotherapy. Immunol Rev 188: 22-32, 2002.

6. Cocchia M, Huber R, Pantano S, Chen EY, Ma P, Forabosco A, Ko MS and Schlessinger D: PLAC1, an Xq26 gene with placenta-specific expression. Genomics 68: 305-312, 2000.

7. Fant ME, Fuentes J, Kong X and Jackman S: The nexus of prematurity, birth defects, and intrauterine growth restriction: A role for plac1-regulated pathways. Front Pediatr 2: 8, 2014.

8. Wang X, Baddoo MC and Yin Q: The placental specific gene, PLAC1, is induced by the Epstein-Barr virus and is expressed in human tumor cells. Virol J 11: 107, 2014.

9. Koslowski M, Sahin U, Mitnacht-Kraus R, Seitz G, Huber C and Türeci O: A placenta-specific gene ectopically activated in many human cancers is essentially involved in malignant cell processes. Cancer Res 67: 9528-9534, 2007.

10. Devor EJ: Placenta-specific protein 1 (PLAC1) is a unique onco-fetal-placental protein and an underappreciated therapeutic target in cancer(J). Integr Cancer Sci Ther 3: 479-483, 2016.

11. Dong XY, Peng JR, Ye YJ, Chen HS, Zhang LJ, Pang XW, Li Y, Zhang Y, Wang S, Fant ME, et al: Placl is a tumor-specific antigen capable of eliciting spontaneous antibody responses in human cancer patients. Int J Cancer 122: 2038-2043, 2008.

12. Chen J, Pang XW, Liu FF, Dong XY, Wang HC, Wang S, Zhang Y and Chen WF: PLAC1/CP1 gene expression and autologous humoral immunity in gastric cancer patients. Beijing Da Xue Xue Bao 38: 124-127, 2006

13. Devor EJ, Reyes HD, Gonzalez-Bosquet J, Warrier A, Kenzie SA, Ibik NV, Miller MD, Schickling BM, Goodheart MJ, Thiel KW, et al: Placenta-specific protein 1 expression in human papillomavirus 16/18-positive cervical cancers is associated with tumor histology. Int J Gynecol Cancer 27: 784-790, 2017.

14. Jackman SM, Kong X and Fant ME: Plac1 (placenta-specific 1) is essential for normal placental and embryonic development. Mol Reprod Dev 79: 564-572, 2012.

15. Old LJ: Cancer is a somatic cell pregnancy. Cancer Immun 7: 19, 2007.

16. Cheever MA, Allison JP, Ferris AS, Finn OJ, Hastings BM, Hecht TT, Mellman I, Prindiville SA, Viner JL, Weiner LM, et al: The prioritization of cancer antigens: A national cancer institute pilot project for the acceleration of translational research. Clin Cancer Res 15: 5323-5337, 2009.

17. GDC Data User's Guide(EB/OL): (2021.08.19). Available from: https://docs.gdc.cancer.gov/Data/PDF/Data_UG.pdf.

18. Subramanian A, Tamayo P, Mootha VK, Mukherjee $\mathrm{S}$, Ebert BL, Gillette MA, Paulovich A, Pomeroy SL, Golub TR, LanderES, et al: Gene setenrichmentanalysis: A knowledge-based approach for interpreting genome-wide expression profiles. Proc Natl Acad Sci USA 102: 15545-15550, 2005. 
19. Liberzon A, Birger C, Thorvaldsdóttir H, Ghandi M, Mesirov JP and Tamayo P: The Molecular Signatures Database (MSigDB) hallmark gene set collection. Cell Syst 1: 417-425, 2015.

20. Schneider CA, Rasband WS and Eliceiri KW: NIH Image to ImageJ: 25 years of image analysis. Nat Methods 9: 671-675, 2012.

21. R Core Team R: A Language And Environment For Statistical Computing. R Foundation For Statistical Computing, Vienna, 2018.

22. Goel MK, Khanna P and Kishore J: Understanding survival analysis: Kaplan-Meier estimate. Int J Ayurveda Res 1: 274-278, 2010.

23. Bradley SD, Talukder AH, Lai I, Davis R, Alvarez H, Tiriac H, Zhang M, Chiu Y, Melendez B, Jackson KR, et al: Vestigial-like 1 is a shared targetable cancer-placenta antigen expressed by pancreatic and basal-like breast cancers. Nat Commun 11: 5332, 2020.

24. Mittal V: Epithelial mesenchymal transition in tumor metastasis. Annu Rev Pathol 13: 395-412, 2018.

25. Goossens S, Vandamme N, Van Vlierberghe P and Berx G: EMT transcription factors in cancer development re-evaluated: Beyond EMT and MET. Biochim Biophys Acta Rev Cancer 1868 584-591, 2017.

26. Liu F, Shen D, Kang X, Zhang C and Song Q: New tumour antigen PLAC1/CP1, a potentially useful prognostic marker and immunotherapy target for gastric adenocarcinoma. J Clin Pathol 68: 913-916, 2015.

27. Wu Y, Lin X, Di X, Chen Y, Zhao H and Wang X: Oncogenic function of Plac1 on the proliferation and metastasis in hepatocellular carcinoma cells. Oncol Rep 37: 465-473, 2017.

28. Liu FF, Dong XY, Pang XW, Xing Q, Wang HC, Zhang HG, Li Y, Yin YH, Fant M, Ye YJ, et al: The specific immune response to tumor antigen CP1 and its correlation with improved survival in colon cancer patients. Gastroenterology 134: 998-1006, 2008

29. Tchabo NE, Mhawech-Fauceglia P, Caballero OL, Villella J, Beck AF, Miliotto AJ, Liao J, Andrews C, Lele S, Old LJ, et al: Expression and serum immunoreactivity of developmentally restricted differentiation antigens in epithelial ovarian cancer. Cancer Immun 9: 6, 2009.

30. Devor EJ and Leslie KK: The oncoplacental gene placenta-specific protein 1 is highly expressed in endometrial tumors and cell lines. Obstet Gynecol Int 2013: 807849, 2013

31. Ghods R, Ghahremani MH, Madjd Z, Asgari M, Abolhasani M, Tavasoli S, Mahmoudi AR, Darzi M, Pasalar P, Jeddi-Tehrani M, et al: High placenta-specific 1/low prostate-specific antigen expression pattern in high-grade prostate adenocarcinoma. Cancer Immunol Immunother 63: 1319-1327, 2014.

32. Pópulo H, Lopes JM and Soares P: The mTOR signalling pathway in human cancer. Int J Mol Sci 13: 1886-1918, 2012
33. Laplante M and Sabatini DM: mTOR signaling in growth control and disease. Cell 149: 274-293, 2012.

34. Kremer CL, Klein RR, Mendelson J, Browne W, Samadzedeh LK, Vanpatten K, Highstrom L, Pestano GA and Nagle RB: Expression of mTOR signaling pathway markers in prostate cancer progression. Prostate 66: 1203-1212, 2006.

35. Wang L, Chang L, Li Z, Gao Q, Cai D, Tian Y, Zeng L and Li M: miR-99a and -99b inhibit cervical cancer cell proliferation and invasion by targeting mTOR signaling pathway. Med Oncol 31: 934, 2014.

36. Rashmi R, DeSelm C, Helms C, Bowcock A, Rogers BE, Rader JL, Grigsby PW and Schwarz JK: AKT inhibitors promote cell death in cervical cancer through disruption of mTOR signaling and glucose uptake. PLoS One 9: e92948, 2014.

37. Kirkwood J. Cancer immunotherapy:The interferon-alpha experience. Semin Oncol 29: 18-26, 2002.

38. Kretzmann NA, Chiela E, Matte U, Marroni N and Marroni CA: $\mathrm{N}$-acetylcysteine improves antitumoural response of Interferon alpha by NF- $\mathrm{B}$ downregulation in liver cancer cells. Comp Hepatol 11: 4, 2012.

39. Harris AL: Hypoxia - a key regulatory factor in tumour growth. Nat Rev Cancer 2: 38-47, 2002.

40. Thomas GV, Tran C, Mellinghoff IK, Welsbie DS, Chan E, Fueger B, Czernin J and Sawyers CL: Hypoxia-inducible factor determines sensitivity to inhibitors of mTOR in kidney cancer. Nat Med 12: 122-127, 2006.

41. Wilson WR and Hay MP: Targeting hypoxia in cancer therapy. Nat Rev Cancer 11: 393-410, 2011

42. Pilch H, Schlenger K, Steiner E, Brockerhoff P, Knapstein P and Vaupel P: Hypoxia-stimulated expression of angiogenic growth factors in cervical cancer cells and cervical cancer-derived fibroblasts. Int J Gynecol Cancer 11: 137-142, 2001.

43. Aiello NM, Maddipati R, Norgard RJ, Balli D, Li J, Yuan S, Yamazoe T, Black T, Sahmoud A, Furth EE, et al: EMT subtype influences epithelial plasticity and mode of cell migration. Dev Cell 45: 681-695.e4, 2018.

44. Wong SHM, Fang CM, Chuah LH, Leong CO and Ngai SC: E-cadherin: Its dysregulation in carcinogenesis and clinical implications. Crit Rev Oncol Hematol 121: 11-22, 2018.

45. Lee JY and Kong G: Roles and epigenetic regulation of epithelial-mesenchymal transition and its transcription factors in cancer initiation and progression. Cell Mol Life Sci 73 4643-4660, 2016

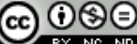

This work is licensed under a Creative Common Attribution-NonCommercial-NoDerivatives 4.0 International (CC BY-NC-ND 4.0) License. 